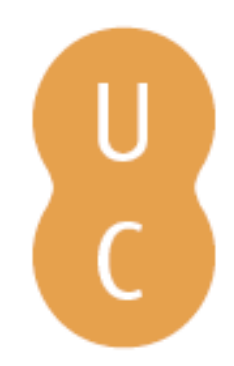

\title{
pombalina
}

\section{El personaje de Antígona en Sófocles y Gambaro: la creación de una nueva tragicidad}
Autor(es):
Coce, María Victoria
Publicado por: Centro de Estudos Clássicos e Humanísticos da Universidade de Coimbra; Imprensa da Universidade de Coimbra URL persistente:
DOI:
DOI:http://dx.doi.org/10.14195/978-989-721-038-9_15
URI:http://hdl.handle.net/10316.2/30178
Accessed : $\quad$ 26-Apr-2023 13:31:14

A navegação consulta e descarregamento dos títulos inseridos nas Bibliotecas Digitais UC Digitalis, UC Pombalina e UC Impactum, pressupõem a aceitação plena e sem reservas dos Termos e Condições de Uso destas Bibliotecas Digitais, disponíveis em https://digitalis.uc.pt/pt-pt/termos.

Conforme exposto nos referidos Termos e Condições de Uso, o descarregamento de títulos de acesso restrito requer uma licença válida de autorização devendo o utilizador aceder ao(s) documento(s) a partir de um endereço de IP da instituição detentora da supramencionada licença.

Ao utilizador é apenas permitido o descarregamento para uso pessoal, pelo que o emprego do(s) título(s) descarregado(s) para outro fim, designadamente comercial, carece de autorização do respetivo autor ou editor da obra.

Na medida em que todas as obras da UC Digitalis se encontram protegidas pelo Código do Direito de Autor e Direitos Conexos e demais legislação aplicável, toda a cópia, parcial ou total, deste documento, nos casos em que é legalmente admitida, deverá conter ou fazer-se acompanhar por este aviso.

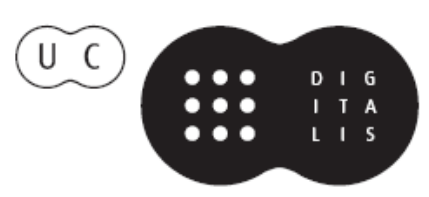




\section{De ayer a hoy}

\section{Influencias clásicas en la literatura}

\section{Aurora López, Andrés Pociña, Maria de Fátima Silva (coords.)}




\title{
El personaje de Antígona en Sófocles y Gambaro: LA CREACIÓN DE UNA NUEVA TRAGICIDAD
}

\author{
María Victoria Coce \\ (UBA-IUNA)
}

\begin{abstract}
El objetivo del trabajo es comparar la construcción del personaje 'Antígona' en los textos de Sófocles y Gambaro, Antígona Furiosa, haciendo hincapié en el concepto de tragicidad que las define como heroínas en dos universos ficcionales opuestos. Partimos de la hipótesis de que el texto de Griselda Gambaro está construido mediante un diálogo intertextual con la obra de Sófocles, pero a partir de una contraposición paródica de las características que definen al personaje sofocleo, especialmente de su carácter trágico. Demostramos que la Antígona de Gambaro resulta un sujeto trágico que desplaza su sentido en la medida en que la 'tragicidad' no depende de la muerte de la heroína, en tanto elemento fundamental para el retablecimiento de la justicia, sino de la insistencia de una muerte infinitamente repetida a partir de una causalidad absurda.
\end{abstract}

\section{Antígona: la tragedia como 'acrecentamiento'.}

Recordamos que la acción dramática sofoclea comienza delante del palacio real en Tebas, y que se inicia con las primeras luces de la madrugada. El prólogo de la obra aparece construido por el diálogo entre Antígona y su hermana Ismene, quienes con sus réplicas informan al público los antecedentes necesarios de la acción. Además dicho preámbulo cumple la función de adelantar el conflicto central de la pieza: Antígona comunica a Ismene el decreto de Creonte de prohibir el entierro de Polinices bajo pena de muerte. Y la invita a cumplir junto con ella el enterramiento debido a pesar de que esto contradiga el decreto de Creonte y de que implique la decisión de morir ${ }^{1}$. La negativa de Ismene plantea ya el denso conflicto trágico de la pieza. La protagonista se desvincula de su hermana, estableciendo claramente el conflicto dramático en términos de una disyunción absoluta: cumplir el deber para con los dioses a pesar de ir en contra de las leyes de la ciudad o traicionar el mandato sagrado ${ }^{2}$. En su parlamento Antígona anuncia que espera una "bella muerte" (kalón thanein ${ }^{3}$ ), siendo ésta, entonces, una consecuencia trágica de su elección y no un funesto fin inevitable. La plantea

\footnotetext{
1 Cf. Sophocle (1955), v. 41-44.

2 Cf. Sophocle (1955), v. 45-46 y 71-76.

3 Cf. Sophocle (1955), v. 72.
} 
como algo bueno para ella, en la medida en que la considera un acto que le permite concordar con la voluntad divina. Pero en el mismo párrafo el poeta deja también planteado la tensión dramática, pues el dilema en el que está puesta Antígona no resulta en ninguno de sus dos términos opuestos un bien absoluto: ella yacerá muerta tras cometer "un piadoso crimen" ${ }^{4}$. Oxímoron que definiría, pues, a esta heroína sofoclea, que con su desmesurada pasión por cumplir con las leyes de los dioses choca con el orden de la ciudad y su reglas. Antígona es piadosa y sacrílega a la vez, genera un desequilibrio que recién se restablecerá después de su muerte.

Finalmente el coro prepara la entrada de Creonte, quien establece un agón con el Corifeo y se empieza a mostrar el exceso de este héroe trágico que pretende con su edicto contra Polinices, regir sobre realidades que están más allá de los vivos ${ }^{5}$. Así, es posible observar que desde el inicio Creonte encierra motivaciones justas, que hacen al orden y al bienestar de la ciudad, pero por otro lado su heroísmo está teñido de hybris, al pretender invadir el dominio de los dioses infernales. Por eso es que el Corifeo empieza a tomar distancia de su gobernante cuando le ordena que vigile y haga cumplir su mandato ${ }^{6}$. En este diálogo aparece por primera vez la asociación entre la idea de la muerte (thánatos) y la de 'acrecentamiento' (tó kérdos), que postulamos como constitutiva del significado que Antígona da a su muerte. Relación que define a su vez la oposición Creonte/Antígona, es decir determina la contradicción protagonista/antagonista, que se resolverá con la muerte, como acto existencial imprescindible para alcanzar el equilibrio perdido tanto de la ciudad como de la heroína, que logra con ello su cometido.

No podemos recoger aquí las citas textuales en donde se relacionan la idea de morir o de muerte (thanéein, thánatos) y acrecentamiento existencial (tó kérdos), pero podemos señalar que reaparecen sistemáticamente y le dan sentido a todo el conflicto que anima la acción dramática, de la cual retomaremos algunos de sus puntos culminantes que nos permitirán constatar lo planteado.

En efecto, luego de que Antígona da sepultura a su hermano y se entera Creonte del hecho, el rey insiste con la motivación del lucro como motor de la desobediencia a su ley ${ }^{7}$ y profiere la amenaza de muerte para los guardias si no entregan al autor del sepelio. En la condena misma reaparece la palabra tó kérdos ${ }^{8}$ y $\operatorname{kerdainein}^{9}$ como única causa del delito, evidenciándose la ignorancia

\footnotetext{
${ }^{4}$ Cf. Sophocle (1955), v. 74.
}

${ }^{5}$ Sophocle (1955), v. 213-214: "en efecto, a ti te es posible servirte de todo tipo de leyes, tanto a cerca de los muertos como de cuantos estamos vivos".

${ }^{6}$ Cf. Sophocle (1955), 215-216.

${ }^{7}$ Cf. Sophocle (1955), v. 289-303.

${ }^{8}$ Cf. Sophocle (1955), v. 310.

${ }^{9}$ Cf. Sophocle (1955), v. 312. 
por parte del gobernante acerca de qué otras implicancias tiene el término en boca de sus oponentes.

En la segunda escena, el Guardia trae a Antígona para entregarla ante el rey. En el interrogatorio se da cuenta de los detalles de rito fúnebre y de los prodigios ocurridos: se revela, en este caso, el segundo indicio temporal que ofrece la pieza, al señalarse que el acto se produjo cuando sol ocupó el medio del cielo. Y se marca, asimismo, la lectura simbólica del huracán hecha por los guardias como indicio de una desgracia divina en ciernes ${ }^{10}$. Antígona, por su parte, asume en este agón su responsabilidad y su destino, fundamentando su accionar en las leyes "inquebrantables y no escritas de los dioses"11. Las plantea como incuestionables y define su propia muerte como tó kérdos (acrecentamiento) ${ }^{12}$. Hecho que, como declara ella misma genera ausencia de sufrimiento ${ }^{13}$, porque tiene esperanzas en el después de la muerte, en reencontrarse con los suyos y ser querida por ellos ${ }^{14}$ y en llegar a ser como la hija de Tántalo, la mítica Níobe ${ }^{15}$, divinidad asociada entre otras cosas con la poesía como una forma de trascendencia. El coro, en efecto, responde a este canto de lamentación de Antígona, recordando el destino de la figura mítica para consolarla, y confirma la idea de que le espera un destino equiparable al de los dioses como el que le tocó a Níobe ${ }^{16}$.

La palabra tó kérdos está también en el centro de la disputa entre Creonte y Tiresias ya que es interpretada con sentidos opuestos: Tiresias trata de convencer al rey de que recapacite respecto de su decisión de matar a Antígona ${ }^{17}$ apelando a una "conveniencia" (tó kérdos) que no es económica. Sin embargo, Creonte retoma el término revirtiendo su sentido y acusando al adivino de corromperse por dinero y de complotarse con los tebanos para atentar contra su poder ${ }^{18}$.

\section{Antígona Furiosa: la tragedia como resentimiento.}

Siguiendo ahora el mismo esquema de análisis, trataremos de destacar la importancia del manejo de la relación acción dramática / flujo temporal, con le objetivo de dar cuenta de la reinterpretación que la autora hace del personaje sofocleo ya que, como en el caso de la Antígona griega, consideramos al personaje como sujeto de la acción dramática, inserto a la vez en un espacio/

\footnotetext{
${ }^{10}$ Cf. Sophocle (1955), v. 415-416.

${ }^{11}$ Cf. Sophocle (1955), v. 454-455.

${ }^{12}$ Cf. Sophocle (1955), v. 461-462: "y si muero antes de tiempo, lo llamo acrecentamiento".

${ }^{13}$ Cf. Sophocle (1955), v.468: "ahora ya no sufro por estas cosas".

${ }^{14}$ Cf. Sophocle (1955), v. 897-904.

${ }^{15}$ Cf. Sophocle (1955), v. 823-833.

${ }^{16}$ Cf. Sophocle (1955), v. 836-838.

${ }^{17}$ Cf. Sophocle (1955), v. 1026-1027.

${ }^{18}$ Cf. Sophocle (1955), v. 1037-1039.
} 
tiempo que configuran el universo ficcional de la obra en el que adquiere sentido.

La acción se inicia cuando Antígona se descuelga de una horca en el ámbito de un bar y comienza a entonar un canto de lamentación por su muerte:

"Antígona (canta).- Se murió y se fue, señora;

El césped cubre su cuerpo,

Hay una piedra a sus pies" ${ }^{19}$.

La canción es interrumpida por las intervenciones de Corifeo y Antinoo, que se burlan negando la muerte:

"Corifeo.- Debiera, pero no hay. ¿Ves césped? ¿Ves piedra? ¿Ves tumba?

Antinoo.- Nada ${ }^{20}$ "

Sin embargo Antígona continúa e introduce otro elemento, el sudario, que más adelante devela su significado: representa el cuerpo muerto de Polinices, agregando de esta manera una gran carga simbólica de sacrificio cruento. Pero la solemnidad de la canción fúnebre aparece denegada, entrecortada por el contexto de burla y por la charla de bar en el que aparece inserta.

Enseguida Corifeo que toma la máscara de Polinices y representa su papel, actúa otra muerte en el escenario, con la cual parodia la de Antígona que acaba de ocurrir y la neutraliza, la denuncia como un hecho teatral, literario. E incluso desarrollan una pequeña versión burlesca de la intriga de toda la pieza, anticipando el tono y el contenido de la acción dramática de la obra:

Antinoo.- ¡Que nadie lo toque! ¡Prohibido! (Como ajena a lo que hace, le saca la corona al Corifeo, la rompe)

Antinoo.- ¡Te sacó la coronita!

Corifeo.- ¡Nadie me enterrará!

Antinoo.- Nadie

Corifeo.- ¡Me comerán los perros! (Jadea estertoroso).

Antinoo.- Pobrecito (Lo abraza. Ríen, se palmean). ${ }^{21}$

Así Corifeo, tomando el papel de Polinices, actúa y se ríe tanto de su muerte como de la condena posterior a no ser enterrado. Mediante el recurso de la duplicación-repetición de la representación teatral en escena obtenemos una nueva versión de la tragedia de Antígona. Además la oposición entre el contenido fatal de la muerte y las acotaciones jocosas de las didascalias provocan un efecto de distanciamiento burlesco del sentido trágico del personaje sofocleo.

Más adelante, la acción central de la pieza es el ritual de la ceremonia fúnebre, que Antígona desarrolla en escena contradiciendo abiertamente a

\footnotetext{
${ }^{19}$ Gambaro (1988), p. 179.

${ }^{20}$ Gambaro (1988), p. 179.

${ }^{21}$ Gambaro (1988), p. 179.
} 
la norma del tirano ${ }^{22}$. Ésta es realizada sin hablar, en presencia de Corifeo y Antinoo quienes actúan de espectadores privilegiados. Una vez más, se reproduce en espejo la situación teatral, en este caso Antígona es protagonista y los otros, dos espectadores que observan la representación del hipotexto sofocleo, del cual ellos por momentos participan, por momento observan y por momentos narran o anticipan ${ }^{23}$.

La invasión de pájaros que lanzan sus excrementos sobre la mesa del bar, signo de la peste desatada por la impureza del cadáver insepulto, hace avanzar la acción dramática y preanuncia la referencia al discurso de Tiresias ${ }^{24}$, quien de ser un aliado de Antígona en el texto de Sófocles, aquí aparece criticado por la heroína. Esto puede ocurrir porque el conflicto ya no está centrado en la oposición ley divina/ley humana, en consecuencia el sacerdote resulta un estorbo y se lo asocia con el poder del estado, como un órgano más de control ${ }^{25}$.

La trama está, pues, diseñada a partir de la narración en pasado de los hechos de la fábula mítica, que a veces es actuada paródicamente por los personajes de la acción dramática, y otras es comentada. En todo momento se desmiente y se provoca un distanciamiento crítico del hipotexto griego a partir del procedimiento de reduplicar y poner al descubierto la ficción teatral. Asimismo el manejo del tiempo, la relación entre hechos en pasado, en presente y en futuro apoya estructuralmente la ambigüedad y el sentido paródico de la acción de Antígona con respecto al original griego. Este nuevo contexto la desautoriza, la burla y la condena sin causas ni razones.

Un pre-final feliz, paródico en donde se niega el contenido del diálogo devela, pues, la farsa mediante el procedimiento de especularidad de una nueva escena teatral dentro de la pieza. En esta ocasión Corifeo toma la máscara de Creonte y actúa su rol, procedimiento que lleva al extremo la metateatralidad:

Corifeo.- ¡Los perdono! ¡No saben lo que hacen! Pretenden condenarme, a mí, que dí mi hijo, mi esposa al holocausto. Antígona que trajiste tantos males sobre mi cabeza y mi casta, ;te perdono!

Antinoo.- (Teatral) ¡Bravo!

(Sale el Corifeo de la carcasa, saluda) ${ }^{26}$

Esto provoca una relectura paródica tanto del arrepentimiento y perdón de Creonte como así también de su condición de héroe trágico. Este falso arrepentimiento actuado por el falso Creonte que es en realidad Corifeo

\footnotetext{
${ }^{22}$ Gambaro (1988) didascalia, p.183.

${ }^{23}$ Cf. Gambaro (1988), p. 183.

${ }^{24}$ Cf. Gambaro (1988), p. 191.

${ }^{25}$ Gambaro (1988), p.191-192.

${ }^{26}$ Gambaro (1988), p. 193.
} 
enmascarado, contrasta también con el final de la pieza, el cual vuelve al conflicto inicial y a negar nuevamente el reconocimiento y el perdón de Creonte:

Antinoo.-Los corazones más duros pueden ablandarse, a último momento. ¿Oíste su llanto? Te perdonó.

Antígona.-No aún quiero enterrar a Polinices. Siempre querré enterrar a Polinices. Aunque nazca mil veces y él muera mil veces.

Antinoo.- ¡Entonces siempre te castigará Creonte! ${ }^{27}$

Los personajes vuelven a oponerse ciegamente como si no hubiera transcurrido la acción dramática y con ella el tiempo. Antígona, resentida e impermeable al diálogo, demuestra una única motivación, enterrar a Polinices, alejada de todo contexto y de toda realidad. De la fábula mítica queda, pues, el enfrentamiento pero llevado al extremo.

Finalmente la acción dramática se cancela cuando la heroína se da muerte a sí misma, volviéndose así al comienzo. La intriga, pues, no sucede de acuerdo con una hilación cronológica, y la disposición de los hechos no guarda tampoco relación de causalidad. Observamos también el mismo procedimiento de inversión en la representación del espacio dramático, en la medida en que el ámbito del bar marca las antípodas de espacio trágico griego, regido por la coherencia de la imitación de acciones y gente nobles. Espacio dramático que concordaba también con una escena carente de actos sangrientos, cuestión que también aparece contradicha. En efecto, el hecho de que Antígona aparezca colgada de una horca en un café con dos hombres burlándose de ella, resulta una inversión paródica tanto del espacio dramático-escénico como del personaje en la medida en que se trivializa el sacrificio. La muerte de la heroína es relativizada en tanto deja de ser un hecho irrepetible, acto único y definitivo, porque lo que resulta eterno es el devenir histórico en el cual no se encuentra solución a las contradicciones. Antígona está furiosa y resentida, declara como objetivo último su deseo ciego y maquinal de enterrar a Polinices. El sacrificio de Antígona viene a dar cuenta del absurdo proceso militar que producía muertes fuera de todo ordenamiento legal, de justicia y de ética. Encontramos en el texto una estructura circular que se erige en testimonio del acto de morir como denuncia y única resistencia al abuso de poder. En este círculo la justicia está ausente, la tensión constitutiva del héroe trágico, y el restablecimiento del orden están, asimismo, ausentes. Y se opone al mediodía de la Antígona sofoclea, punto máximo de acercamiento con el mundo divino, momento de ritual funerario. Se opone al camino de la acción que acompaña al ocaso del día, una trama que guarda concordancia entre el orden cósmico, temporal y

\footnotetext{
${ }^{27}$ Gambaro (1988). p. 193.
} 
divino, un universo ficcional que finaliza junto con la muerte acompañando el ciclo vital. La realidad en la ciudad de Tebas cambió luego del sacrificio de Antígona, pero este discontinuum, aparece inscripto en el continuum de la eternidad del mundo, de la justicia de los dioses, y de la eterna convivencia de la heroína con sus seres queridos y con los dioses. Lo que el mito de Antígona eterniza es la inserción de la conducta humana en el ciclo cósmico y divino. La muerte de Antígona es 'acrecentamiento' porque restablece una dike que presupone un existir posterior incondicionado. 


\section{Bibliografía}

Sophocle (1955), Antigone, Paris, Les Belles Lettres.

Gambaro, Griselda (1988), Antígona Furiosa, en Gestos, Abril. 